\title{
Knowledge, Attitude and Practice on Electronic Cigarette and their Associated Factors among Undergraduate Students in a Public University
}

\author{
Nuurain Amirah MR, Tengku Amatullah Madeehah TM, Nadeeya 'Ayn MN, Dzulkhairi MR, \\ Mohamed Fakhri AB, Shalinawati R, Zairina AR, Nooriah MS, Jaafar H. \\ Public Health Unit, Department of Primary Health Care, Faculty of Medicine and Health Sciences, Universiti Sains Islam Malaysia
}

\section{ABSTRACT}

INTRODUCTION: Smoking tobacco has been a longstanding issue worldwide, but the trend of smoking electronic cigarette (e-cigarette) is now on the rise. Many people assume that smoking e-cigarette is safer and less harmful than conventional cigarette smoking, which is worrying. Adolescents and young adults are easily influenced by advertisements on e-cigarette. Thus, this study was conducted to determine the knowledge, attitude and practice on e-cigarette among university students. MATERIALS AND METHODS: A cross-sectional study using selfadministered questionnaire was carried out among 484 university students in a public university in Negeri Sembilan, Malaysia. RESULTS: Respondents were between 19- 25 year-old undergraduates, with the majority being female. $6.6 \%$ of the respondents were smokers, with nine having tried e-cigarette, where only one is a regular user. Bivariate analysis was carried out to analyse knowledge, attitude and practice scores on e-cigarette. There was significant association between gender with attitude and practice scores $(p<0.001)$ on e-cigarettes, household income with attitude and practice scores ( $\phi=0.013$ and $p=0.001$ respectively) on e-cigarette, as well as smoking status $(p<0.001)$. Multivariate analysis revealed that being female and non-smoker were associated with higher attitude and practice scores on e-cigarette. CONCLUSION: In conclusion, the knowledge, attitude and practice on e-cigarette needs to be improved among young adults and a more holistic intervention strategy should be implemented to prevent the rise of e-cigarette smoking.

KEYWORDS: e-cigarette, vape, university students, smoking, tobacco.

\section{INTRODUCTION}

In recent years, the usage of electronic cigarette (e-cigarette) or more popularly known as 'vape' has become a trend among young adults in Malaysia. A nationwide study in Malaysia reported that majority of the current e-cigarette users are from the 25-44 year-old age group. Of concern, $86.5 \%$ of the respondents started vaping as early as 19 years of age. ${ }^{1}$ Similarly, in

\section{Corresponding Author:}

Dr. Mohd Hafiz Jaafar Public Health Unit, Department of Primary Health Care, Faculty of Medicine and Health Sciences,

Universiti Sains Islam Malaysia,

Persiaran Ilmu, Putra Nilai,

71800, Nilai, Negeri Sembilan.

Tel: 03-42892400

Email: dr.hafizjaafar@usim.edu.my the United States, a survey among young adults revealed that those aged between 18-24 years old were more likely to try e-cigarette than those of $31-35$ years old. ${ }^{2}$ Despite the inconclusive health outcomes and forbidden (haram) status of vaping from the National Fatwa Council of Malaysia, ${ }^{3}$ e-cigarette has remained popular in Malaysia. ${ }^{3,4}$

Smoking e-cigarette or vaping is the behaviour of inhaling vapourised solution from an electronic device that consists of a battery, automatic or manual switch, heating element and reservoir of flavoured liquid solution. ${ }^{5}$ Despite the scarcity of long-term evidence on health from vaping, vapours produced from e-cigarette have been found to trigger similar immune responses caused by conventional cigarette smoking. In a scientific 
review, frequent or short-term levels of exposure to fine and ultrafine particles from e-cigarettes can contribute to pulmonary and systemic inflammatory processes. 6 Carcinogenic compounds, such as diethylene glycol, lead, chromium, nickel and tobacco specific Nnitrosamines, have been found in e-cigarette cartridges, solutions and mist in varying amounts.7,8 Centre for Tobacco Products, Food and Drug Administration (FDA) in the USA stated that from 2008 to 2012, they received 47 adverse events reports on e-cigarettes. ${ }^{9}$ Several flavours and concentrations of e-cigarette liquids exist but the sources of ingredients and their manufacturing processes are unclear. ${ }^{10}$

Previous studies reported that many people have false perception towards smoking e-cigarette. In general, people view that vaping is harmless, ${ }^{11,12}$ cheaper compared to conventional smoking, ${ }^{13,14}$ non-polluting to the public, ${ }^{11,15,16}$ and act as an effective smoking cessation tool. ${ }^{12}$ However, the FDA has not approved ecigarette as a smoking cessation tool. Prior studies revealed that more than $70 \%$ of their respondents have heard of e-cigarette. ${ }^{12,17-19}$ But several studies have reported poor level of knowledge on e-cigarette. A study in the USA reported that almost a quarter of e-cigarette users $(23 \%)$ were uncertain regarding harmful effects when comparing between e-cigarette and conventional cigarette. $^{20}$ Another study revealed that more than half $(57.3 \%)$ did not know that some e-cigarettes contain nicotine. ${ }^{21}$ Findings from a study among undergraduate students in Manila also reported $96.1 \%$ of students have poor knowledge with regards to design, chemical content, possible health effects, and regulation of ecigarettes. $^{22}$ There is scarcity of publication regarding knowledge and awareness of vaping in Malaysia. Therefore, this study is aimed to determine the level of knowledge, attitude and practice on e-cigarette, and their associated factors among university students, focusing on students with a background from Islamic secondary school.

\section{MATERIAL AND METHODS}

\section{Study Design}

A cross-sectional study among 484 undergraduate students was conducted in Universiti Sains Islam Malaysia (USIM) from June 2016 to December 2016.
Since the study was aimed at testing the knowledge on e-cigarette incorporating the knowledge from the Islamic perspective, USIM was chosen because it is the only public university in Malaysia that put formal Islamic education during secondary school as the entry requirement for its undergraduate program. Ethical approval was obtained from USIM ethical committee under the research code PPP/USG-0116/ FPSK/30/11416.

\section{Sample Selection}

Respondents were recruited via proportionate simple random sampling method based on the number of students from each faculty. Based on sample size calculation using OpenEpi software version 3.03a, with an additional of $20 \%$ anticipated non-responders, the minimum sample size required was 288 respondents. The inclusion criteria were undergraduate students who were willing to participate, have no physical or mental disability, and able to read and understand Bahasa Malaysia.

\section{Study Instrument}

A self-constructed questionnaire was used as a measuring tool to collect the data. It was pre-tested among Tamhidi students (Matriculation program in USIM). The questionnaire was constructed by the researchers based on "adapt-and-adopt" method from previous knowledge, attitude \& practice (KAP) study on tobacco smoking. ${ }^{23}$ A content validation was done and the questionnaire was reviewed by five experts namely public health physician, epidemiologist and family medicine specialist. The reliability of this questionnaire was calculated using Cronbach's Alpha statistical method with a value of 0.74 .

The questionnaire was constructed in Bahasa Malaysia and structured into five parts. The first part consists of respondent's socio-demographic background such as age, sex, year of study, parent's monthly income, and marital status. The second section identified the respondents' smoking status regarding e-cigarette, as well as whether they knew anybody around them who smoked e-cigarette. The third, fourth, and fifth parts of the questionnaire examined their knowledge, attitude and practice towards e-cigarette respectively. 
The level for each score components (knowledge, attitude, practice) were measured by the accumulated scores obtained. There were 11 questions pertaining to knowledge. The participants need to choose either they agreed or disagreed with the statements given. The questions were then scored 2 for correct answer, 1 for not sure and 0 for wrong answer. As for the attitude part, a total of 4 questions were included and the scoring was based on the 5-point Likert rating scale. For the positive statements, the scores were $5=$ strongly agreed, 4=agreed, 3=not sure, 2=disagreed, and 1=strongly disagreed. For the negative statements, the scores were $5=$ strongly disagreed, $4=$ disagreed, $3=$ not sure, $2=$ agreed, and $1=$ strongly agreed. The last part of the questionnaire was practice, which consisted 4 questions. The scores given were $2=$ good practice, $1=$ moderate practice and $0=$ bad practice. The maximum scores were 22 for knowledge, 20 for attitude and 8 for practice. Data from the questionnaire was coded and entered into SPSS version 23 for statistical analysis.

\section{Data analysis}

Descriptive analysis was conducted to determine the prevalence and sociodemographic factors of the study population. Results for continuous data were presented as mean and standard deviation (median and interquartile range for skewed data). For categorical data, the results were presented as frequency and percentage. Bivariate analysis was done to establish any relationship between the exposure variables (sociodemographic factors) with the outcome variables (KAP scores). For bivariate analysis, level of significance was pre-set at 0.05. Independent T-test (Mann-Whitney if the data were skewed) was conducted to determine the association between all the exposure and the outcome variables. Pearson correlation test (Spearman correlation test for skewed data) was used to determine the correlation between age, total knowledge, attitude and practice scores. For multivariate analysis, generalized linear model was used. Variables with significant results in the bivariate analysis were included in the multiple linear regression analysis. For multiple linear regression, significance level was pre-set at 0.05 and variables with $p$-value of $<0.05$ were then included in the final regression model.

\section{RESULTS}

\section{Descriptive Analysis}

\section{Socio-demographic Characteristics}

Table I shows the distribution of sociodemographic characteristics of the respondents. A total of 484 respondents participated the study, 140 males and 344 females aged between 19-25 years old with mean (SD) age of 20.95 (0.91). All but three were single. Household income ranged between RM 400 and RM 30,000 with a median (IQR) income of RM 4,000 (6,100).

\section{Smoking background}

Among the 484 respondents, $32(6.6 \%)$ of them were smokers and all were male. $9(28.1 \%)$ of the smokers have tried e-cigarette. $23(71.9 \%)$ of the smokers smoked conventional cigarette, while only 3 (9.4\%), 9

Table I. Distribution of respondents by socio-demographic, smoking backgrounds, knowledge, attitude and practice towards e-cigarette $(n=484)$.

\begin{tabular}{|c|c|c|}
\hline Variables & $\mathbf{N}$ & $\%$ \\
\hline \multicolumn{3}{|l|}{ AGE (YEARS OLD) } \\
\hline 19 & 5 & $(1.1)$ \\
\hline 20 & 165 & $(34.1)$ \\
\hline 21 & 189 & $(39.0)$ \\
\hline 22 & 104 & $(21.5)$ \\
\hline 23 & 17 & $(3.5)$ \\
\hline 24 and 25 & 4 & $(0.9)$ \\
\hline \multicolumn{3}{|l|}{ MARITAL STATUS } \\
\hline Single & 481 & $(99.4)$ \\
\hline Married & 3 & $(0.6)$ \\
\hline \multicolumn{3}{|l|}{ GENDER } \\
\hline Male & 140 & $(28.9)$ \\
\hline Female & 344 & $(71.1)$ \\
\hline \multicolumn{3}{|c|}{ MONTHLY HOUSEHOLD INCOME $(\mathrm{RM})(\mathrm{N}=463)$} \\
\hline$<3000$ & 170 & $(36.7)$ \\
\hline $3000-5000$ & 128 & $(27.7)$ \\
\hline$>5000$ & 165 & $(35.6)$ \\
\hline \multicolumn{3}{|l|}{ SMOKING STATUS } \\
\hline Yes & 32 & $(6.6)$ \\
\hline No & 452 & $(93.4)$ \\
\hline \multicolumn{3}{|l|}{$\begin{array}{l}\text { EVER TRIED E- } \\
\text { CIGARETTE }(\mathrm{N}=30)\end{array}$} \\
\hline Yes & 9 & $(30.0)$ \\
\hline No & 21 & $(70.0)$ \\
\hline \multicolumn{3}{|c|}{ AGE OF SMOKING INITIATION (N=27) } \\
\hline $6-12$ years old & 4 & $(14.8)$ \\
\hline $13-15$ years old & 12 & $(44.4)$ \\
\hline $16-17$ years old & 5 & $(18.5)$ \\
\hline 18 years and above & 6 & $(22.3)$ \\
\hline \multicolumn{3}{|c|}{ RELATIVES/ FRIENDS USING E-CIGARETTE } \\
\hline Close family & 73 & $(16.2)$ \\
\hline members & 40 & $(8.8)$ \\
\hline Relatives & 220 & $(48.7)$ \\
\hline Friends & 119 & $(26.3)$ \\
\hline
\end{tabular}


(28.1\%) and $15(46.9 \%)$ have tried cigar, hand-rolled, and shisha respectively. Despite 452 (93.4\%) respondents being non- smoker themselves, it is possible that they are passive smokers as they might be surrounded by smokers. $16.2 \%(n=73)$ and $8.8 \%(n=40)$ of non-smoker respondents have close family members and relatives respectively who used e-cigarette, almost half ( $n=220,48.7 \%$ ) have friends, and about a quarter of them ( $n=119,26.3 \%)$ have neighbours who smoked e -cigarette.

\section{Knowledge, Attitude, and Practice related to e-cigarette}

From a total of 22 marks in the knowledge section, more than half of the respondents $(n=271,56.0 \%)$ obtained a score of more than $50 \%$ with a mean (SD) score of 5.80 (2.04), a minimum score of zero was obtained by three respondents $(0.6 \%)$, and a maximum of 22 were scored by three respondents.

The respondent's attitude score on e-cigarette had a total score of 20 with a median (IQR) score of 18.0 (4.0). As for the practice related to e-cigarette smoking, the median score (IQR) laid at 7.0 (1.0).

For the knowledge part, most of the respondents answered correctly for questions 1, 2, 4, 5, 8, 9 and 11 (marks ranging from 1.46 to 1.84). However, majority of them were unsure whether i) e-cigarette contained nicotine, ii) nicotine content has been standardized by Ministry of Health $(\mathrm{MOH})$, iii) National Fatwa Council had declared that e-cigarette is forbidden in Islam.
However, they agreed that e-cigarette is one of the ways to stop smoking.

For attitude, majority of the respondents strongly agreed that the selling of e-cigarette should be banned $(n=302$, $62.4 \%$ ) and Muslim should not use e-cigarette $(n=371$, $76.7 \%$ ). Majority of the respondents also disagreed $(n=166,34.3 \%)$ and strongly disagreed $(n=199,41.1 \%)$ that e-cigarette will not cause addiction to the users.

For practice, majority of the respondents cannot stay near to the individuals who is using e-cigarette $(n=377$, $77.9 \%$ ) and will be not be influenced by their friends who used e-cigarette $(n=453,93.6 \%)$. Most of the respondents will also advice their family members to stop using e-cigarette ( $\mathrm{n}=379,78.3 \%$ ).

\section{Bivariate Analysis}

Bivariate analysis (Table II) found that no factors had significant association with knowledge scores. As for attitude and practice, gender $(\mathrm{p}<0.001)$, household income $(\mathrm{p}=0.02$ and $\mathrm{p}=0.013)$ and smoking status $(p<0.001)$ were found to be significantly associated with both attitude and practice scores towards e-cigarette. Between knowledge, attitude, and practice towards ecigarette, significant positive correlations were seen between attitude and practice scores, but the correlations were weak and moderate respectively ( $r=0.333$, $\mathrm{p}<0.001)$. There was also significant correlation found between knowledge and practice scores towards e-cigarette $(p=0.029)$, however the relationship found was a weak negative correlation $(r=-0.100)$.

Table IIa. Results of bivariate analysis between age, gender, household income, smoking status with knowledge, attitude and practice towards e-cigarette $(\mathrm{n}=484)$.

\begin{tabular}{|c|c|c|c|c|c|c|c|c|c|c|c|}
\hline \multirow[t]{2}{*}{ Variables } & \multirow[t]{2}{*}{$\mathbf{N}$} & \multirow[t]{2}{*}{$\%$} & \multicolumn{3}{|c|}{ Knowledge score } & \multicolumn{3}{|c|}{ Attitude score } & \multicolumn{3}{|c|}{ Practice score } \\
\hline & & & $\begin{array}{l}\text { Mea } \\
\mathrm{n}\end{array}$ & SD & $p$-value & $\begin{array}{l}\text { Mea } \\
\mathrm{n}\end{array}$ & SD & $p$-value & $\begin{array}{l}\text { Mea } \\
\mathrm{n}\end{array}$ & SD & $p$-value \\
\hline \multicolumn{12}{|c|}{ GENDER } \\
\hline Male & 140 & 28.9 & 15.7 & 2.39 & 0.498 & 16.1 & 3.04 & $<0.001$ & 5.3 & 1.82 & $<0.001$ \\
\hline Female & 344 & 71.1 & 15.3 & 2.25 & & 17.9 & 2.09 & & 6.7 & 1.18 & \\
\hline \multicolumn{12}{|c|}{ SMOKING STATUS } \\
\hline Smoker & 32 & 6.6 & 15.2 & 2.52 & 0.67 & 14.1 & 2.81 & $<0.001$ & 3.8 & 2.02 & $<0.001$ \\
\hline $\begin{array}{l}\text { Non- } \\
\text { smoker }\end{array}$ & 452 & 93.4 & 15.5 & 2.28 & & 17.7 & 2.35 & & 6.5 & 1.34 & \\
\hline
\end{tabular}


Table IIb. Results of bivariate analysis between age, gender, household income, smoking status with knowledge, attitude and practice towards e-cigarette $(n=484)$.

\begin{tabular}{llccc}
\hline Variables & & Knowledge score & Attitude score & Practice score \\
\hline AGE & $\mathrm{r}$ & -0.04 & -0.014 & 0.082 \\
& $p$-value & 0.385 & 0.753 & 0.07 \\
HOUSEHOLD INCOME & $\mathrm{r}$ & 0.071 & -0.108 & -0.116 \\
& $p$-value & 0.126 & $\mathbf{0 . 0 2}$ & $\mathbf{0 . 0 1 3}$ \\
KNOWLEDGE & $\mathrm{r}$ & 1 & -0.026 & 0.054 \\
ATTITUDE & $p$-value & $\cdot$ & 0.571 & 0.233 \\
& $\mathrm{r}$ & -0.026 & 1 & 0.333 \\
PRACTICE & $p$-value & 0.571 &. & $<\mathbf{0 . 0 0 1}$ \\
& $\mathrm{r}$ & 0.054 & 0.333 & 1 \\
\hline
\end{tabular}

\section{Multivariate Analysis}

Significant bivariate results were included in the multivariate analysis. These include gender, household income and smoking status. The results for final regression model for multivariate analysis using generalized linear model showed that gender and smoking were significantly associated with attitude. Female students and non-smokers have better attitude scores. The mean attitude score among males is 1.231 units lower compared to females, and 2.631 units higher among non-smokers compared to smokers (Table III). Similar results were obtained for factors associated with practice (Table IV), whereby gender and smoking status were found to be significantly associated with higher practice scores. The mean practice score among the males is 1.033 units lower compared to female, and 1.925 units higher among non-smokers compared to smokers. The results for final regression model were summarized in Table III for attitude and Table IV for practice.

Table III. Final regression model of factors associated with attitude score towards e-cigarette smoking.

\begin{tabular}{lcccc}
\hline \multirow{2}{*}{ Variables } & \multirow{2}{*}{ B } & \multirow{2}{*}{$\boldsymbol{p}$ value } & \multicolumn{2}{c}{ 95\% CI } \\
\cline { 4 - 5 } (Intercept) & 15.318 & & Lower & Upper \\
Male & -1.231 & $<0.001$ & -1.728 & -0.734 \\
Female & 1 & & & \\
Non-smoker & 2.632 & $<0.001$ & 1.725 & 3.539 \\
Smoker & 1 & & & \\
\hline
\end{tabular}

\section{DISCUSSION AND CONCLUSION}

Many studies found that smoking habits start during the adolescent years. ${ }^{24-26}$ In this study, the prevalence was low possibly due to the higher number of female respondents participating in the study, nevertheless, it may not be the only reason as the number of female adolescent smokers has doubled within five years from 2.1\% in 2012 to $5.3 \%$ in 2017.27,28 Approximately 1 in 4 male respondents in our study smoked cigarette, which corresponds to the statistics of adult smokers in Malaysia. ${ }^{27}$ When we examined the age of smoking initiation, it did not differ from previous studies, whereby the initial age of smoking was as early as six years old. This was supported by the findings of a local study, which found that smoking habits among Malaysians began as early as pre-school age. ${ }^{29}$ Similar to other local and abroad surveys, the majority of the respondents started their habits during their early secondary school ages. ${ }^{29-31}$

Table IV. Final regression model of factors associated with practice score towards e-cigarette smoking.

\begin{tabular}{lcccc}
\hline \multirow{2}{*}{ Variables } & \multirow{2}{*}{ B } & \multirow{2}{*}{$\boldsymbol{p}$ value } & \multicolumn{2}{c}{ 95\% CI } \\
\cline { 4 - 5 } (Intercept) & 4.814 & & Lower & Upper \\
Male & -1.033 & $<0.001$ & -1.316 & -0.751 \\
Female & 1 & & & \\
Non-smoker & 1.925 & $<0.001$ & 1.409 & 2.44 \\
Smoker & 1 & & & \\
\hline
\end{tabular}

The prevalence of e-cigarette smoking in this study was quite low compared to the national Tobacco \& E-cigarette Survey Among Malaysian Adolescents (TECMA) which found that $9.1 \%$ of adolescent were ecigarette users. ${ }^{32}$ Despite that, the issue of e-cigarette is undeniably an important issue among university students, since the use of these smokeless tobacco among Malaysian adults has tremendously increased from $0.8 \%$ in 2011 to $11.5 \%$ in $2015.27,33$ Despite not being smokers themselves, the students are exposed to 
the dangers of e-cigarette from surrounding people or even family members. In this study, the overall knowledge on e-cigarette is considerably low among the students. However, in a study conducted in another local university with Islamic education, the level of knowledge on smoking among their students and workers was found to be high. ${ }^{23}$ Given that half of the participants in that study were university staff, it is possible that they have more knowledge on e-cigarette compared to students. The percentage of respondents in our study who were unsure of the contents inside the cigarette was similar to the findings in a study in Pakistan. ${ }^{34}$ When asked whether it contained nicotine, slightly more than half (53.1\%) answered 'yes' and only $28.5 \%$ respondents answered that it does not contain tar.

Regarding the Islamic knowledge on e-cigarette, despite having Islamic education embedded into the undergraduate syllabus, not all participants knew the Islamic ruling on e-cigarette. Only 54.5\% were certain that smoking e-cigarette posed the same rule of being impermissible as regular cigarette, and only $43.0 \%$ were aware that it has been declared as such by National Fatwa Council, Malaysia. ${ }^{3}$

The overall attitude scores in the present study showed that many of the respondents are opposed to e-cigarette smoking. This concurs with two other studies among university students in Philippines as well as adults in Hong Kong, but the opposite was found in a study among adolescents in California. ${ }^{22,35,36}$ This suggests that the attitude towards e-cigarette varies across communities and countries, most likely due to the difference in culture and lifestyle.

As for the practice against e-cigarette smoking, most of them $(78.3 \%)$ will and have advised family members to stop smoking e-cigarette. This is much higher than what was found in a study on practices regarding smoking cessation in Hong Kong. ${ }^{36}$ On the other hand, although many of them $(77.9 \%)$ preferred not to sit or be around people who smoke e-cigarettes, only $27.7 \%$ of the respondents are willing to lodge a report to authorities regarding knowledge of any premises involved in an illegal e-cigarette business.

\section{Association between socio-demographic factors and knowledge, attitude and practice}

Although household income was found to have significant association with tobacco use among adults in Malaysia, 37 the association with attitude and practice opposing e-cigarette behaviour among the students had only weak correlations $(r=-0.115$ and $r=0.153$ respectively). No significant association was seen with knowledge. Similarly, a study by Lozano et al. (2015) found that among university students in Philippines, socio-economic status did not contribute to any differences in the knowledge, attitude and practice towards opposing e-cigarette smoking. ${ }^{22}$

Gender differences were found in the knowledge, attitude and practice scores towards opposing ecigarette. Male students were found to have higher knowledge scores (mean $(\mathrm{SD})=6.31$ (2.06)) compared to female (mean $(\mathrm{SD})=5.60(2.00)$ ). The finding was in line with another study that reported young women have relatively poor knowledge on smoking behavior. ${ }^{34,38,39}$ This is probably due to the differences in their risk perception and risk-taking behaviour, which may influence the male participants to explore more information on risk-taking behaviour. 40 Our results however differs from another study which emphasized that female participants have higher knowledge on smoking than the male, but their finding was not significant. ${ }^{23}$ Despite the higher knowledge among male students in this study, their mean scores for attitude and practice were lower than the female students. This is further supported by a study among teenagers, where they noticed female had less positive outlooks and perception towards e-cigarette compared to male. ${ }^{34}$ This could also be attributed to the differences between gender in perceiving and practicing risk-taking behavior. ${ }^{40}$

Another factor associated with better attitude and practice was smoking status. Smokers were found to have lower scores for attitude and practice. Attitude against tobacco use among non-smokers was also observed to be prevalent in a study conducted among 2489 adults. ${ }^{41}$ It is not surprising that those who have tried e-cigarette have more positive perceptions towards e-cigarette. ${ }^{42}$ Perhaps, because they have tried themselves and felt no difference in health or other 
effects. In another study, adolescents who smoked cigarettes were identified to have more positive believe towards e-cigarette and were more willing to try e-cigarette compared to non-smoking adolescents. ${ }^{43}$ The differences in practice were also prominent between smokers and non-smokers. Although knowledge was found not to have significant association with smoking status, the mean score of knowledge on e-cigarette was higher among smokers compared to non-smokers. This shows that smokers have more awareness and knowledge on e-cigarette, which is in agreement with a study conducted in Pakistan. ${ }^{39}$

\section{Association between Knowledge, Attitude and Practice}

In our study, we found that having high knowledge on e -cigarette was associated with higher attitude score. A study conducted in the United States reported that having high knowledge on smoking was associated with better attitude, thus leading to effective tobacco control. ${ }^{41}$ This association also concurs with a local study among university staff and workers.23 The association between knowledge and practice was found to have a negative relationship. Students with higher knowledge on e-cigarettes had lower practice scores. When analysed according to smoking status, smokers were found to have similar knowledge scores compared to non-smokers but their practice scores were significantly lower compared to the same group. Thus, having more knowledge about e-cigarette does not translate into practices that is opposed to the behaviour. A positive relationship was seen between attitude and practice. Students having higher attitude scores were found to have higher practice scores. Therefore, instituting a more negative perception on e-cigarette smoking would improve the community awareness and culture.

\section{Limitation of study}

Despite the increasing trend in vape use based on the national evidence, our study noted a very low prevalence of vape use among the students, which the inconsistencies could be due to the limitation in this study. Given the sensitive nature of smoking issues especially among religious background students, under reporting might have contributed to the low prevalence. On top of that, in general, university students have just surpassed the legal age of smoking. They might still have the 'guilt' insight of smoking as what they perceived during their school days, which could influence their willingness to disclose their smoking status. Furthermore, this study was participated by female students as majority of respondents. We have tried selecting the students in random manner, however, many male participants refused to join probably due to the sensitive issues which might create discomfort among the students although anonymity of respondents were assured.

\section{CONCLUSION}

Our study revealed that the prevalence of vape use is low among the participants. Despite that, as cigarette and e-cigarette smoking are crucial issues in the societies, they should have a good knowledge regarding the matter. However, our study has revealed that university students, who were still young, were insufficiently exposed to the knowledge on e-cigarette smoking. Knowledge on tobacco smoking and its health effect including on e-cigarette and other forms of tobacco consumption should be instilled in schools as many of them had started their habits since then. Community awareness towards e-cigarette should be improved to create a healthier culture. Lastly, government should implement policies with regard to controlling the impact of e-cigarette.

\section{CONFLICT OF INTEREST}

The authors declare that there is no conflict of interest regarding the publication of this article.

\section{ACKNOWLEDGEMENTS}

We would like to thank Universiti Sains Islam Malaysia (USIM) for providing the USIM Research Grant (Research Project Code: PPP-FPSK-11416-00) for this study, as well as allowing the research to be conducted among the students in US. 


\section{REFERENCES}

1. Ab Rahman NS, Nik Mohamad H, Ab Rahman J, Kartiwi M, Draman S, Shafie AA, et al. Characteristics of E-cigarette or vape (ECV) users and patterns of use: Malaysia chapter. Med J Malaysia. 2017;72(supplemetary 1):53.

2. Biener L, Song E, Sutfin E, Spangler J, Wolfson M. Electronic cigarette trial and use among young adults: reasons for trial and cessation of vaping. Int J Environ Res Public Health. 2015;12(12):16019-26.

3. JAKIM. Muzakarah Putuskan Vape Haram [online]. Available at: https://www.bharian.com.my/berita/ nasional/2015/12/107224/majlis-fatwa putuskan-vapeharam. Accessed Dec 1, 2020

4. Drummond MB, Upson D. Electronic cigarettes. Potential harms and benefits. Ann Am Thorac Soc. 2014;11(2):236-42.

5. McQueen A, Tower S, Sumner W. Interviews with 'vapers': implications for future research with electronic cigarettes. Nicotine Tob Res. 2011;13(9):860-7.

6. Grana R, Benowitz N, Glantz SA. E-cigarettes: a scientific review. Circulation. 2014;129(19):197286.

7. Westenberger BJ. Evaluation of E-cigarette [online]. Available at: https://www.fda.gov/ downloads/drugs/scienceresearch/ucm173250.pdf. Accessed Dec 1, 2020.

8. Williams M, Villarreal A, Bozhilov K, Lin S, Talbot P. Metal and silicate particles including nanoparticles are present in electronic cigarette cartomizer fluid and aerosol. PLoS One. 2013;8 (3):p.e57987.

9. Chen IL. FDA summary of adverse events on electronic cigarettes. Nicotine Tob Res. 2013;15 (2):615-6.

10. Schaller K, Ruppert L, Kahnert S, Bethke C, Nair U, Pötschke-Langer M. Electronic Cigarettes -An Overview. Red Series: Tobacco Prevention and Tobacco Control. Heidelberg; 2013. [online] Available at: https://www.dkfz.de/en/presse/ download/RS-Vol19-E-Cigarettes-EN.pdf

11. Dockrell M, Morrison R, Bauld L, McNeill A. Ecigarettes: prevalence and attitudes in Great Britain. Nicotine Tob Res. 2013;15(10):1737-44.

12. Pepper J, Ribisl K, Emery S, Brewer N. Reasons for starting and stopping electronic cigarette use. Int J Environ Res Public Health. 2014;11(10):10345-61.

13. Etter, J.F. and Bullen C. Electronic cigarette: users profile, utilization, satisfaction and perceived efficacy. Addiction. 2011;106(11):2017-28

14. Dawkins, L., Turner, J., Roberts, A. and Soar K. 'Vaping'profiles and preferences: an online survey of electronic cigarette users. Addiction. 2013;108 (6):1115-25.

15. Foulds J, Veldheer S, Berg A. Electronic cigarettes (e-cigs): views of aficionados and clinical/public health perspectives. Int J Clin Pract. 2011;65 (10):1037-42.

16. Kong G, Morean ME, Cavallo DA, Camenga DR, Krishnan-Sarin S. Reasons for electronic cigarette experimentation and discontinuation among adolescents and young adults. Nicotine Tob Res. 2014;17(7):847-54.

17. Zhu, S.H., Gamst, A., Lee, M., Cummins, S., Yin, L. and Zoref L. The use and perception of electronic cigarettes and snus among the US population. PLoS One. 2013;8(10):p.e79332.

18. Berg CJ, Barr DB, Stratton E, Escoffery C, Kegler M. Attitudes toward e-cigarettes, reasons for initiating e-cigarette use, and changes in smoking behavior after initiation: a pilot longitudinal study of regular cigarette smokers. Open J Prev Med. 2014;4 (10):789-800.

19. Tan AS, Bigman CA. E-cigarette awareness and perceived harmfulness: prevalence and associations with smoking-cessation outcomes. Am J Prev Med. 2014;47(2):141-9.

20. Sutfin EL, McCoy TP, Morrell HE, Hoeppner BB, Wolfson M. Electronic cigarette use by college students. Drug Alcohol Depend. 2013;131(3):21421.

21. Sanders-Jackson, A.N., Tan, A.S., Bigman, C.A. and Henriksen L. Knowledge about e-cigarette constituents and regulation: results from a national survey of US young adults. Nicotine Tob Res. 2014;17(10):1247-54.

22. Lozano P, David V, Sabino A, Salvedia K, Vilarta JR. Awareness, Knowledge, Attitudes, and Practices (AKAP) toward Electronic Cigarettes among 3rd and 4th Year Undergraduate Students of the University of the Philippines Manila. Manila; 2015.

23. Nurul 'Izzati AH, Nor Azlina AR, Nor Iza AR, Mainul H. Knowledge, Attitude and Practice towards Smoking among International Islamic University Malaysia Kuantan Communities. Int Med J Malaysia. 2016;15(2):19-26.

24. Al-Sadat N, Misau AY, Zarihah Z, Maznah D, Su 
TT. Adolescent tobacco use and health in Southeast Asia. Asia Pacific J Public Heal. 2010;22

(supplementary 3):175S-180S.

25. Everett, S.A., Warren, C.W., Sharp, D., Kann, L., Husten, C.G. and Crossett LS. Initiation of cigarette smoking and subsequent smoking behavior among US high school students. Prev Med (Baltim). 1999;29(5):327-33.

26. Hwang, J.H. and Park SW. Age at smoking initiation and subsequent smoking among Korean adolescent smokers. J Prev Med Public Heal. 2014;47(5):266-72.

27. Institute for Public Health. National Health and Morbidity Survey 2015: Report on Smoking Status Among Malaysian Adults 2015 [online]. Available at: https://www.moh.gov.my/moh/resources / NHMS2015-VolumeV.pdf

28. Institute for Public Health. National Health and Morbidity Survey 2017: Adolescent Health Survey 2017 [online]. Available at: http://iku.moh.gov.my/ images/IKU/Document/REPORT/NHMS2017/ NHMS2017Infographic.pdf

29. Lim HK, Ghazali SM, Kee CC, Lim KK, Chan YY, Teh HC, et al. Epidemiology of smoking among Malaysian adult males: prevalence and associated factors. BMC Public Health. 2013;13(1):8.

30. Chotbenjamaporn P, Haruhansapong V, Jumriangrit P, Pitayarangsarit S, Agarwal N, Garg R. Tobacco use among thai students: Results from the 2015 global youth tobacco survey. Indian J Public Health. 2017;61(5):40-6.

31. Veeranki, S.P., John, R.M., Ibrahim, A., Pillendla, D., Thrasher, J.F., Owusu, D., Ouma, A.E. and Mamudu HM. Age of smoking initiation among adolescents in Africa. Int J Public Health. 2017;62 (1):63-72.

32. Institute of Public Health Malaysia. Tobacco \& ECigarette Survey Among Malaysian Adolescents (TECMA). Kuala Lumpur: Institute of Public Health Malaysia; 2016 [online]. Available at: http:// www.iku.gov.my/images/IKU /Document/ REPORT/TECMA2016/

TabaccoandECigarette.pdf

33. Institute for Public Health. Report of the Global Adult Tobacco Survey (GATS) Malaysia 2011 [online]. Available at: http://www.iku.gov.my/ index.php/ research/iku/gats

34. Shaikh A, Ansari HT, Ahmad Z, Shaikh MY,
Khalid I, Jahangir M, et al. Knowledge and Attitude of Teenagers Towards Electronic Cigarettes in Karachi, Pakistan. Cureus. 2017;9(7).

35. Gorukanti A, Delucchi K, Ling P, Fisher-Travis R, Halpern-Felsher B. Adolescents' attitudes towards e-cigarette ingredients, safety, addictive properties, social norms, and regulation. Prev Med (Baltim). 2017;94:65-71.

36. Leung DY, Chan SS, Fu IC, Lam TH. Knowledge, attitudes and practices regarding smoking cessation among Chinese affiliates of women's organisations in Hong Kong. Health Soc Care Community. 2011;19(2):207-16.

37. Lim KH, Lim HL, Teh CH, Kee CC, Khoo YY, Ganapathy SS, et al. Smoking among school-going adolescents in selected secondary schools in Peninsular Malaysia-findings from the Malaysian Adolescent Health Risk Behaviour (MyaHRB) study. Tob Induc Dis. 2017;15(1):9.

38. Manaf RA, Shamsuddin K. Smoking among young urban Malaysian women and its risk factors. , 20(3), pp.204-213. Asia Pacific J Public Heal. 2008;20 (8):204-13.

39. Ghazal S, Akhter S, Aziz HW, Warraich UA, Shah WH, Javed U, et al. Knowledge, attitude and perception regarding e-cigarette among post graduate medical trainees in Pakistan. Eur Respir J. 2016;48:PA2028.

40. Reniers RL, Murphy L, Lin A, Bartolomé SP. and Wood SJ. Risk perception and risk-taking behaviour during adolescence: the influence of personality and gender. PLoS One. 2016;11(4):p.e0153842.

41. Blake KD, Viswanath K, Blendon RJ and Vallone D. The role of tobacco-specific media exposure, knowledge, and smoking status on selected attitudes toward tobacco control. Nicotine Tob Res. 2009;12 (2):117-26.

42. Choi K, Forster J. Characteristics associated with awareness, perceptions, and use of electronic nicotine delivery systems among young US Midwestern adults. Am J Public Health. 2013;103 (3):556-61.

43. Pepper JK, Reiter PL, McRee AL, Cameron LD, Gilkey MB, Brewer NT. Adolescent males' awareness of and willingness to try electronic cigarettes. , 52(2), pp.144-150. J Adolesc Heal. 2013;52(2):144-50. 